\title{
Improvement in cognitive impairment following the successful treatment of endogenous Cushing's syndrome-a case report and literature review
}

\author{
Malgorzata Monika Brzozowska ${ }^{1,2,3^{*}} \mathbb{D}$, Sacha Kepreotis ${ }^{1}$, Fiona Tsang ${ }^{1}$ and Sully Xiomara Fuentes- Patarroyo ${ }^{1}$
}

\begin{abstract}
Background: Endogenous Cushing's syndrome, a rare endocrine disorder, characterised by chronic cortisol hypersecretion, results in neuropsychiatric disturbances and in cognitive deficits, which are only partially reversible after the biochemical remission of the disease.

Case presentation: We report a case of a woman with a profound cognitive deficit and a gradual functional decline caused by Cushing's disease of at least 10 years duration. The neurosurgical resection of her $2 \mathrm{~mm}$ adrenocorticotropic hormone (ACTH) secreting pituitary microadenoma resulted in a successful resolution of the patient's hypercortisolism and a significant recovery of her neurocognitive function. The patient's progress was evaluated using serial clinical observations, functional assessments, Mini-Mental Status exams and through the formal neuropsychological report. Furthermore, the patient's recovery of her neurocognitive function was reflected by a sustained improvement in the patient's specific structural brain abnormalities on radiological imaging.

Conclusions: This report illustrates the importance of early detection and treatment of Cushing's syndrome in order to prevent neurocognitive impairment and neuropsychiatric disorders which are associated with an endogenous cortisol hypersecretion. The long term adverse effects of severe hypercortisolaemia on brain function and the pathophysiological mechanisms responsible for the structural and functional changes in brain anatomy due to glucocorticoid excess are reviewed.
\end{abstract}

Keywords: Cushing's syndrome, Cognitive deficit, Functional decline, Microvascular ischaemic changes, Transsphenoidal excision, Pituitary microadenoma

\section{Background}

Cushing's disease (CD), a rare disorder with an incidence of 1.2-1.7 per million population per year [1], is caused by a disruption of the hypothalamus-pituitary-adrenal (HPA) axis with a pathological increase in circulating cortisol secondary to excessive adrenocorticotropic hormone $(\mathrm{ACTH})$ production. The cortisol excess is associated with increased mortality due to serious comorbidities including systemic arterial hypertension, insulin resistance with diabetes mellitus, hypercoagulable

\footnotetext{
* Correspondence: m.brzozowska@unsw.edu.au

${ }^{1}$ Endocrinology Department, Sutherland Hospital, Sydney, NSW, Australia ${ }^{2}$ Faculty of Medicine, University of New South Wales, Kensington, NSW, Australia

Full list of author information is available at the end of the article
}

state and decreased bone mineral density [2, 3]. Additionally CD results in neuropsychiatric disturbances with major depression and generalized anxiety disorders being diagnosed in $54-81 \%$ of patients with CD [4] well as in neurocognitive deficits with memory impairments, deficits in visual and spatial information, reasoning and verbal intellectual skills and memory recall $[5,6]$. Sustained exposure to glucocorticoid excess can induce hippocampal atrophy and cerebral remodelling via numerous pathological mechanisms including decreased glucose utilisation, disruptions in neuronal homeostasis, as well as aberrations in neurotransmitter signalling [5] [7]. The limited studies evaluated the long-term effects of chronic overexposure to cortisol, such as in

(c) The Author(s). 2019 Open Access This article is distributed under the terms of the Creative Commons Attribution 4.0 International License (http://creativecommons.org/licenses/by/4.0/), which permits unrestricted use, distribution, and reproduction in any medium, provided you give appropriate credit to the original author(s) and the source, provide a link to the Creative Commons license, and indicate if changes were made. The Creative Commons Public Domain Dedication waiver (http://creativecommons.org/publicdomain/zero/1.0/) applies to the data made available in this article, unless otherwise stated. 
$\mathrm{CD}$, on the brain. The majority of these studies pointed to the long standing deficits affecting verbal skills and visual memory despite biochemical remission [8].

We report a case of a woman with a profound cognitive deficit and a gradual functional decline caused by the $\mathrm{CD}$ of at least 10 years duration. The neurosurgical resection of her $2 \mathrm{~mm}$ ACTH secreting pituitary microadenoma resulted in a successful reversal of patient's hypercortisolism and a significant recovery of her cognitive function, evident at 3.5 years after her neurosurgery.

\section{Case presentation}

A 59-year-old woman, previously independent in activities of daily living and self-employed in the family business, presented with a progressive, over the period of 10 years, decline in cognitive function manifested as increasing social withdrawal, inattentiveness followed by progressive memory impairment, inappropriate behaviour, urinary incontinence and problems with balance. Furthermore she had episodes of an emotional lability, alternating between depressive symptoms with psychomotor retardation and agitation with paranoid ideation, insomnia and confusion. Patient's presentation was complicated by a spontaneous $(8 \mathrm{~mm})$ subdural haematoma treated with craniotomy and evacuation in year 2014 as well as by a single seizure during the perioperative period with a subsequent pulmonary embolism requiring temporary use of anticoagulation. Despite surgical evacuation of her subdural haematoma, patient's cognitive status continued to deteriorate due to superimposed episodes of delirium requiring multiple, 2nd monthly hospitalisations. Comprehensive geriatric assessment, performed in between hospitalisations, confirmed an impairment of the patient's executive function with impaired reasoning and problem solving skills. Her MiniMental state examination (MMSE), a brief (5-10 min) mental status questionnaire, assessing attention, orientation, memory, language and visuospatial copying, revealed a score of 24/30, suggestive of cognitive decline. 3 months prior to the neurosurgery her executive function severely declined to the point of requiring fulltime assistance with all daily living activities including her personal care and the need for regular antipsychotics and antidepressants with haloperidol, mirtazapine and levetiracetam. On her preoperative assessment (Barthel Index of activities of daily living, total score range from 0 to 20) the patient scored only 7 points, indicative of her severe limitations in activities of daily living [9].

The patient's past medical history included hypertension, type 2 diabetes mellitus, thyrotoxicosis successfully resolved with I-131 treatment, osteoporosis with L5 vertebral compression fracture, recurrent urinary tract infections requiring supra-pubic catheterisation and hyperandrogenism with an onset after 40 years of age.

\section{Presentation and investigations}

The patient had mild phenotypic Cushingoid features including round face, central obesity, skin thinning and buffalo hump, mild facial hirsutism, kyphosis without vertebral tenderness and mild proximal myopathy.

The initial investigations revealed raised serum cortisol at $768 \mathrm{nmol} / \mathrm{L}$ (Reference range (RR) 155-599) with normal ACTH of $35.1 \mathrm{pg} / \mathrm{mL}$ (RR between 7.2 to 62.3 ), Table 1. Her 24-h urine free cortisol was raised at 413 $\mathrm{nM} / 24 \mathrm{~h}(\mathrm{RR}<166)$ with a $24-\mathrm{h}$ urine creatinine of 10 $\mathrm{mmol} / 24 \mathrm{~h}$. An overnight $1 \mathrm{mg}$ dexamethasone suppression test showed non-suppressed serum cortisol of 122 $\mathrm{nmol} / \mathrm{L}$ [10] with ACTH of $18.5 \mathrm{pg} / \mathrm{mL}$. The results of inferior petrosal vein sampling were consistent with Cushing syndrome of pituitary origin, Table 1 .

The patient had negative human immunodeficiency virus (HIV) and syphilis serology.

The patient's initial magnetic resonance imaging (MRI) of the brain showed extensive white matter disease, in excess of expected for patient's age, involving both hemispheres, consistent with severe chronic small vessel ischaemia and moderate cerebral atrophy. A subsequent MRI with targeted pituitary views showed a 2 $\mathrm{mm}$ pituitary adenoma in the mid portion of the pituitary gland, Fig. 1 The prolonged EEG revealed no evidence of any epileptiform activity.

\section{Treatment}

A stereotactic endoscopic transphenoidal excision of the pituitary microadenoma was performed (11 November 2015). Histopathological analysis of the tumour revealed positive immunostaining for $\mathrm{ACTH}$, equivocal immunostaining for prolactin with negative immunostaining for $\mathrm{GH}, \mathrm{FSH}, \mathrm{LH}, \mathrm{TSH}$ and $\mathrm{p} 53$. The proliferation index assessed by Ki-67 was less than $1 \%$.

\section{Outcome and follow up}

The post-operative MRI brain showed no evidence of residual pituitary disease. Her serum cortisol level, which was measured on the fourth postoperative day, has decreased to $108 \mathrm{nmol} / \mathrm{L}$, together with ACTH level of $3.6 \mathrm{pg} / \mathrm{mL}$. The patient was commenced on a supraphysiological prednisolone dose of $10 \mathrm{mg} /$ day to reduce her postoperative glucocorticoid withdrawal syndrome. The choice of glucocorticoid replacement therapy was influenced by the patient's preference for once-daily glucocorticoid dosing. The patient had an uneventful post-operative recovery with a weaning regime of prednisolone up to 12 months post neurosurgery.

As the patient's prolactin level remained raised on repeated measurements, despite gradual withdrawal of antipsychotic medications, the patient was commenced on cabergoline for a period of 6 months $(0.25 \mathrm{mg}$ a week) with a subsequent decline in serum prolactin from 
Table 1 Results of initial laboratory tests

\begin{tabular}{|c|c|c|}
\hline Parameters & Parameter Value & Reference interval \\
\hline Sodium (mmol/L) & 138 & $135-145$ \\
\hline Potassium (mmol/L) & 5.0 & $3.6-5.1$ \\
\hline Bicarbonate (mmol/L) & 24 & $22-32$ \\
\hline eGFR $(\mathrm{mL} / \mathrm{min})>90$ & 77 & $>90$ \\
\hline Fasting glucose (mmol/L) & $9.7^{*}$ & $3.0-7.8$ \\
\hline $\mathrm{HbA1c}(\%)(\mathrm{mmol} / \mathrm{mol})$ & 7.9 & $<6(42)$ \\
\hline Albumin (g/L) & 37 & $33-48$ \\
\hline Alanine aminotransferase $(\mathrm{U} / \mathrm{L})$ & 18 & $<45$ \\
\hline Aspartate aminotransferase (U/L) & 18 & $<45$ \\
\hline Alkaline phosphatase $(U / L)$ & 66 & $38-126$ \\
\hline$\gamma$-Glutamyl transferase (U/L) & 22 & $0-30$ \\
\hline Bilirubin (umol/L) & 6 & $0-25$ \\
\hline Free T4 (pmol/L) & 17.3 & $12-22$ \\
\hline Free T3 (pmol/L) & 3.5 & $3.1-6.8$ \\
\hline TSH (mIU/L) & 1.5 & $0.27-4.2$ \\
\hline Testosterone (nmol/L) & 3.3 & $0-1.7$ \\
\hline Androgen free index (\%) & 12 & $0-4.6$ \\
\hline DHEAS (umol/L) & 12.9 & $2.1-8.7$ \\
\hline $\mathrm{LH}(\mathrm{mlU} / \mathrm{ml})$ & 11.3 & $>30$ \\
\hline FSH (mIU/L) & 81.7 & $20-90$ \\
\hline Prolactin (mU/L) & 662 & $102-496$ \\
\hline IGF1 (nmol/L) & 25 & $3.8-29.8$ \\
\hline Haemoglobin (g/L) & 143 & $115-165$ \\
\hline Platelets (× 109/L) & 295 & $150-450$ \\
\hline \multicolumn{3}{|l|}{ Confirmation of Cushing syndrome } \\
\hline 0800 cortisol (nmol/L) & 768 & $155-599$ \\
\hline $\mathrm{ACTH}(\mathrm{pg} / \mathrm{mL})$ & 35.1 & $7.2-63.3$ \\
\hline $24 \mathrm{~h}$ urinary free cortisol (nmol/day) & 413 & $(<166)$ \\
\hline Urine creatinine $(24 \mathrm{~h})$ & 10 & $(6.0-18)$ \\
\hline $\begin{array}{l}\text { Cortisol post } 1 \mathrm{mg} \text { dexamethasone } \\
\text { suppression test }(\mathrm{nmol} / \mathrm{L})\end{array}$ & 122 & $155-599$ \\
\hline ACTH post $1 \mathrm{mg}$ dexamethasone suppression test $(\mathrm{pg} / \mathrm{mL})$ & 18.5 & $7.2-63.3$ \\
\hline $\begin{array}{l}\text { Cortisol post } 8 \mathrm{mg} \text { dexamethasone } \\
\text { suppression test }(\mathrm{nmol} / \mathrm{L})\end{array}$ & 109 & $155-599$ \\
\hline ACTH post $8 \mathrm{mg}$ dexamethasone suppression test $(\mathrm{pg} / \mathrm{mL})$ & 12.6 & $7.2-63.3$ \\
\hline BIPSS: Central-to-peripheral ACTH maximal ratio (baseline) & 17.4 & $\geq 2$ \\
\hline $\begin{array}{l}\text { BIPSS: Central-to-peripheral ACTH maximal ratio } \\
\text { (5 min after CRH stimulation) }\end{array}$ & 9.7 & $\geq 3$ \\
\hline
\end{tabular}

* ACTH adrenocorticotropic hormone, BIPSS Bilateral inferior petrosal sinus sampling, DHEAS dehydroepiandrosterone sulfate, eGFR estimated glomerular filtration rate, FSH follicle-stimulating hormone, LH luteinising hormone, IGF1 Insulin-like growth factor, TSH thyroid-stimulating hormone; bolded results are outside of the reference range

$758 \mathrm{mU} / \mathrm{L}$ to $299 \mathrm{mU} / \mathrm{L}$ (2016). Her prolactin levels remain within the reference range after cabergoline cessation. The patient remains in remission from her Cushing syndrome with the last measured $24 \mathrm{~h}$ urinary free cortisol (13 February 2019) being $91 \mathrm{nmol} / 24 \mathrm{~h}$.
At 5 weeks post transphenoidal resection the patient was noticeably more engaging, spontaneous and alert than previously, although still exhibited difficulty with higher order thinking and memory recall. At 5 months the patient continued to display excellent clinical 




A



B

Fig. 1 Preoperative MRI showing small pituitary microadenoma. Legend: Coronal MRI views show altered signal intensity within adenohypophysis T2 weighted sequence (Panel a), a region of delayed enhancement on the dynamic sequences (Panel $\mathbf{b}$ )

recovery, demonstrating appropriate and spontaneous conversation together with an improvement in short term memory recall and restoration of functional performance with household tasks and she no longer required antipsychotic medications. By 17 months post-surgery, the patient's cognitive function has further improved with complete reinstatement of her articulation, language and verbal fluency. The patient regained full functional independence with activities of daily living and furthermore, she was able to reassume her duties helping with the family business finances, an improvement reflected by increased postoperative Barthel Index scores to 18 out of maximum 20 points (year 2017). Her mood has improved and therefore she no longer required treatment with antidepressants. The recent (year 2018) MMSE examination, revealed a total score of 30/30. A more comprehensive neuropsychological assessment, performed 3.5 years after the successful neurosurgery (April 2019), revealed deficits in multiple cognitive domains including executive function with difficulty planning and organising, short term memory impairment for visually presented material and deficit in language with poor performance on confrontational word naming ability. The overall assessment was consistent with a mild cognitive impairment in a 63 year old woman, which was related to her previous CD.

Progress MRI of the brain revealed significant reduction in the extent of the cerebral hemispheric and pontine "microvascular ischaemic changes", Fig. 2

Notably the patient experienced resolution of her metabolic abnormalities with improved blood pressure control and resolution of her diabetes with subsequent cessation of her antihypertensive and glucose lowering therapy.

\section{Discussion}

Metabolic disorders are uncommon but potentially reversible causes of progressive dementia. The potentially reversible causes of cognitive decline due to dementia account for less than $10 \%$ of dementia presentations. Furthermore less than $1 \%$ of these dementia cases have been fully reversible with treatment, usually improving within the first 2 years of diagnosis [11].

We present the case of the patient with CS of at least 10 years duration who initially presented with severe cognitive impairment, affecting multiple functional domains, depression, memory deficits, verbal and language disturbance. The severe cognitive impairment resulted in patient requiring complete assistance with daily activities with a meaningful psychiatric involvement and regular treatment with the antipsychotic agents. The successful neurosurgical excision of her $2 \mathrm{~mm}$ pituitary adenoma resulted in dramatic reversibility of her cognitive impairment and her depressive disorder. Furthermore, there was a significant reversibility of the cerebral hemispheric and pontine "microvascular ischaemic changes"and reduction in the ventricular size together with an improved scoring in assessments of her cognitive function and physical disability.

In the present case, due to the severity of patient's illness, her initial and postoperative cognitive assessments included serial clinical observations, mental status questionnaires together with functional assessments of her activities of daily living. Notably, the MMSE scoring may significantly underestimate cognitive impairment in a large proportion of individuals including patients affected by a mood disorder [12, 13]. As our patient's cognitive dysfunction has remarkably improved during her first postoperative 6 months, the patient was reluctant to undergo early neuropsychological testing to examine more discrete aspects of her cognitive functioning. The results of her detailed neuropsychological tests, performed at 3 years after her CS treatment, although indicative of the residual functioning impairment and 




Fig. 2 Resolution of small vessel ischemia following the pituitary adenoma resection. Legend: Imaging studies obtained before and after treatment. Axial and sagittal FLAIR MRI images show the progressive resolution of microvascular ischaemic changes in the brainstem and cerebral hemispheres over time. Baseline (Panels $\mathbf{a}$ and $\mathbf{d}$ ), at 2 years (Panels $\mathbf{b}$ and $\mathbf{e}$ ) and at 3 years after resection of pituitary adenoma (Panels $\mathbf{c}$ and $\mathbf{f}$ )

deficits in her visuospatial short term memory, point to a significant recovery of her brain cognitive function and ongoing remission from her $\mathrm{CD}$.

Endogenous glucocorticoid excess in CS has profound effects on the human brain. Patients with active CS demonstrate cognitive impairments that may affect their concentration, learning and memory as well as cause mood disorders including depression, euphoria and anxiety [14]. Compared to healthy controls, patients treated for $\mathrm{CD}$ demonstrate impaired verbal functions, in particular learning [15-20], impaired quality of life [21], a higher prevalence of psychopathology (e.g. affective disorders especially major depression and apathy) and maladaptive personality traits [20]. Interestingly, the presence of psychopathology is significantly associated with older age, female gender, higher pre-treatment 24-h urinary cortisol levels, a more severe clinical condition and an absence of pituitary adenoma [22].

The prolonged exposure to high levels of endogenous cortisol may have deleterious, long-lasting effects on the hypothalamic-pituitary-adrenal (HPA)-axis with the irreversible structural brain abnormalities and overall brain atrophy. The review of past studies of patients with active Cushing's syndrome consistently points to profound structural brain abnormalities with cortical atrophy, smaller hippocampal volume [23] and increased third ventricle and bicaudate diameters [24]. The glucocorticoid excess may affect important centres for learning and memory resulting in widespread changes in white matter, hippocampus and medial temporal lobe (MTL) encompassing amygdala and the anterior cingulate cortex (ACC) [24-28]. A recent study demonstrated smaller grey matter volumes of the bilateral cerebellar hemispheres in patients with active CS compared with controls [29]. Furthermore, children with CS were found to have smaller cerebral volumes, larger ventricles and smaller amygdala in comparison with healthy controls with a subsequent cognitive decline despite reversal of brain atrophy 1 year after resolution of CS [17]. The study of adolescents with chronic endogenous hypersecretion of cortisol, examined by functional magnetic resonance imaging (fMRI), revealed the functional alterations in amygdala and hippocampus [30].

The use of the new imaging techniques such as magnetic resonance imaging (MRI) and ${ }^{18} \mathrm{~F}$-fluorodeoxyglucose positron emission tomography, further advance our understanding of functional deficits in people with CS. The recent meta-analysis of 19 studies with 339 patients examined brain characteristics in patients with CS (active and in remission) using structural $(N=14)$ and functional $(N=5)$ magnetic resonance imaging [8]. The regional brain neurochemistry was explored in three studies with proton magnetic resonance spectroscopy (H-MRS) while two studies investigated patients' brain activity with functional MRI (fMRI) [8]. Additionally, radiological findings from nine studies were linked with an assessment of patients' cognitive function. Patients with active CS, in comparison to healthy controls, were affected by cerebral atrophy with smaller hippocampal and cerebellar cortex volumes as well as by reduced 
amygdala with coexistent alterations in neurochemical concentrations and brain functional activity [17, 24, 28, 29 , 31]. The brain neuronal dysfunction resulted in altered brain metabolites with decrease in the choline to creatinine ratio $(\mathrm{Cho} / \mathrm{Cr}$ ) in frontal (by $24 \%$ ) and thalamic (by 17\%) areas as compared to healthy subjects [31]. Two fMRI studies pointed to changes in brain structures responsible for an emotional processing [30, 32]. Interestingly, the study, which examined brain function in adolescents, noted their preserved affect and cognition despite functional alterations in amygdala and hippocampus suggesting that phenotypic responses to glucocorticoid excess vary depending on patients' age and stage of their brain maturation [31].

The study of 92 patients with CS, examined by ${ }^{18} \mathrm{~F}$ fluorodeoxyglucose positron emission tomography confirmed a link between impaired brain metabolism in several brain regions such as hippocampus, amygdala, cerebellum, frontal and occipital cortex and elevated cortisol levels [33]. Moreover, the results from this study pointed to the potential for the recovery of brain function after cortisol correction with the presence of transient hypometabolism instead of permanent neuronal loss in brain areas involved in the regulation and action of glucocorticoids. The direct evidence linking prolonged endogenous hypercortisolism with subsequent neuronal dysfunction resulting in mood disturbances, in particular anxiety, comes from measurements of altered brain metabolites by proton magnetic resonance spectroscopy $\left({ }^{1} \mathrm{H}\right.$-MRS) [34]. Taken together, these findings imply that glucocorticoid excess influences the metabolic activity in brain regions with abundant corticosteroid receptors and thus will facilitate exploration of the mechanisms of cognitive disorders in patients with abnormal glucocorticoid levels.

There is a paucity of literature data reporting brain characteristics in CS patients who sustained long term remission from their disease. Furthermore the interpretations of results from these studies is complicated by their different designs, heterogeneity of examined samples, different imaging modalities and duration of follow up ranging from 3.4 to 11.9 years [8]. In the majority of these studies the observed loss of brain volume has only partly recovered after biochemical cure with widespread reductions in white matter integrity $[7,25]$ with partial increase in hippocampal volume which correlated significantly with the reduced urinary free cortisol [35]. The limbic structures, especially the hippocampus, express the high levels of the mineralocorticoid (MR) and glucocorticoid receptors (GR) with high sensitivity to glucocorticosteroids [36]. The metabolism of glucocorticoids is regulated by enzymes 11-beta-hydroxysteroid dehydrogenases (11b-HSDs) [37]. Polymorphisms in the (GR) gene may contribute considerably to the diverse individual responses to the glucocorticoids [38]. The variability in the expression of GR in pituitary and adrenocortical cells may alter the sensitivity of the hypothalamus-pituitary-adrenal (HPA) axis with subsequent differences in body composition and metabolic factors [38]. The ER22/23EK polymorphism of GR gene has been associated with partial form of GC resistance [39] while BclI and N363S polymorphisms have been linked with higher GC sensitivity [40, 41].GR polymorphisms in BclI and N363S as well in 1 $\beta$-HSD1 may increase individual predisposition to mood disorder including depression [42, 43]. Interestingly, recent reports have cautiously linked genetic variants of GR with the degree of postoperative neuropsychiatric disorders in CS patients. In a previous study, the polymorphisms in 11

-HSD type 1 and NR3C1 Bcl1 genes influenced the severity of cognitive impairments in processing and reading speed, auditory attention and working memory together with fatigue [44]. The molecular mechanisms of these observations remain largely unexplained; therefore, much more must be learned about the HPA axis and its regulation.

The previous studies have shown consistently that cognitive deficits in people in remission from CS have improved with change in hippocampal size $[15,45,46]$ with substantial improvements in clinical and behavioural outcomes of treated patients during their first postoperative year [47]. Following intervention to reduce glucocorticoids, CD patients show nearly $10 \%$ hippocampal volume increases after 1.5 to 2 year [35]. The extent of anatomical abnormalities on MRI findings correlated to changes in patients' behaviour and mood [48], improved learning as assessed by neuropsychological test performances [45] and altered decision making [49]. The degree of cognitive impairment and cerebral atrophy were associated with patients' age, age at the time of diagnosis, duration of symptoms [28] and with changes in selective biochemical parameters, in particular with examined cortisol levels [23].

Therefore, the structural and neurochemical abnormalities in both grey- and white matter are not completely reversible at long-term remission and are accompanied by psychological symptoms and impairments in cognitive functioning $[7,8]$. In line with our report, the study of thirty-three patients with CS (11 active, 22 cured) noted that verbal and visual memory was worse in CS patients than controls, even after biochemical cure [18]. The recent functional magnetic resonance imaging of 19 women with CS in remission of median 7 years (IQR 6-10) duration identified decreased functional brain responses in the prefrontal cortex and hippocampus [50]. The episodic and working memory testing linked these memory deficits with changes in the prefrontal cortex, a key region for cognitive function, as well as with decreased functional brain response in the hippocampus during episodic memory encoding [50]. 
Interestingly, the limited studies have shown negative impact of raised prolactin on a range of neurocognitive domains encompassing memory and executive function, anxiety and depressive behaviour as well as in regulation of stress responses [51-55]. Furthermore, recent study demonstrated that treatment of hyperprolactinemia with cabergoline resulted in a cognitive enhancement in patients with prolactin-secreting pituitary adenomas [56]. Mechanisms responsible for the cognitive deficits in patients affected by hyperprolactinaemia have not been fully explored. The limited in vivo or ex vivo animal studies linked hyperprolactinemia with the modulation of nonspatial cognitive tasks [54]. The recent cross-sectional clinical study of female patients with prolactinomas, examined with MRI scans, demonstrated decrease in grey matter volume (GMV) in the left hippocampus and prefrontal cortex. These observed structural brain abnormalities were linked to the deficits in verbal memory and executive function on neuropsychological testing [57].

The treatment of CS in our patient resulted in an improvement in patient's hyperandrogenism with the marked reduction in testosterone and DHEAS levels. The androgens play numerous, important roles in neurocognitive function and mood stability with the powerful effects on executive functioning. Androgens act through binding to intracellular androgen receptor proteins, localised in the multiple brain regions, with the high concentrations in hypothalamic and limbic regions [58, 59]. Interestingly, the studies examining the effects of testosterone on cognition have produced conflicting results. The testosterone has been shown to exert sex-specific effects with both positive and negative influences on cognitive performance. The Dehydroepiandrosterone (DHEA) and its sulfate bound form (DHEAS) have neuroprotective effects and antiglucocorticoid activity [60]. The low androgen levels have been associated with reduced cognitive function, poorer general sense of well-being, impairment of sexual function and depressive symptoms in elderly age [61-63]. Low androgen levels have been reported as a risk factor for development of Alzheimer disease in men [64] while for women, their free testosterone level was negatively associated with verbal fluency, semantic memory, and episodic memory [65]. Importantly, testosterone therapy improved the physical and emotional well-being as well as sexual function of postmenopausal women [66-68]. Conversely, in the group of postmenopausal women, higher testosterone concentration was associated with lower scores for verbal and visual memory, processing and psychomotor speed, executive functions, complex attention and cognitive flexibility [69].

\section{Conclusions}

In summary, we report a case of a woman with a profound cognitive deficit and a functional decline, who after the successful cure of her CS, experienced a significant recovery of her neurocognitive function, reflected by changes in structural brain abnormalities on her MRI imaging. Her presentation, although illustrative of acute and long-term detrimental effects of hypercortisolaemia on brain function, at the same time indicates the potential for the significant recovery of the neurocognitive impairment in patients affected by the endogenous glucocorticoid excess. Notably, patients with CS, despite the long-term cure, may not regain their premorbid level of functioning and continue to experience persistent impairment of their quality of life and their cognitive function. These persistent symptoms following transient hypercortisolism are not well understood and highlight the importance of early detection and treatment.

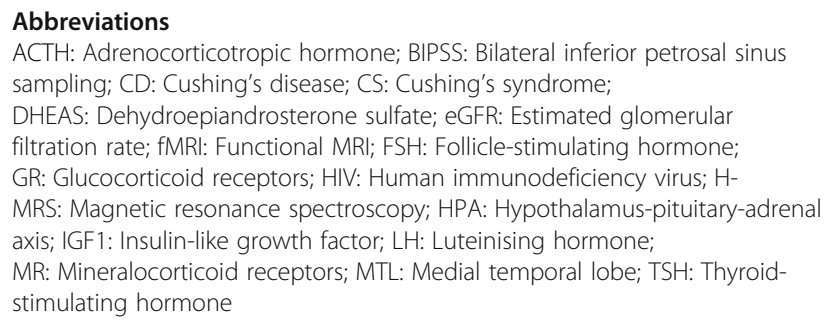

\section{Acknowledgements}

We would like to thank Mrs. Megan Forbes for performing the neuropsychological assessment on our patient.

\section{Authors' contributions}

MMB wrote the first draft of the manuscript and revised it critically for an important intellectual content. She gave the final approval to the submitted version. Dr. SFP prepared the figures for the manuscript and participated in revising the manuscript critically for an important intellectual content. Dr. SK and Dr. FT contributed to the writing of the draft of this manuscript. MM B diagnosed the patient. MMB and SFP both treated the patient. All authors read and approved the final manuscript

\section{Funding}

No funding was obtained for this study.

\section{Availability of data and materials}

The datasets supporting the conclusions of this article are included within the article.

\section{Ethics approval and consent to participate}

This case report involves a patient. The case report complies with the Helsinki Declaration.

\section{Consent for publication}

Written informed consent for the publication of this case report and any accompanying images was obtained from the patient. A copy of the written consent is available for review by the Editor of this journal.

\section{Competing interests}

The authors declare that they have no competing interests.

\section{Author details}

'Endocrinology Department, Sutherland Hospital, Sydney, NSW, Australia.

${ }^{2}$ Faculty of Medicine, University of New South Wales, Kensington, NSW,

Australia. ${ }^{3}$ Garvan institute of Medical Research, Darlinghurst, NSW, Australia. 


\section{Received: 30 November 2018 Accepted: 23 June 2019}

Published online: 28 June 2019

\section{References}

1. Lindholm J, Juul S, Jorgensen JO, Astrup J, Bjerre P, Feldt-Rasmussen U, et al. Incidence and late prognosis of cushing's syndrome: a population-based study. J Clin Endocrinol Metab. 2001;86(1):117-23.

2. Pivonello R, De Leo M, Cozzolino A, Colao A. The treatment of Cushing's disease. Endocr Rev. 2015;36(4):385-486.

3. Nieman LK. Cushing's syndrome: update on signs, symptoms and biochemical screening. Eur J Endocrinol. 2015;173(4):M33-8.

4. Feelders RA, Pulgar SJ, Kempel A, Pereira AM. The burden of Cushing's disease: clinical and health-related quality of life aspects. Eur J Endocrinol. 2012;167(3):311-26.

5. Starkman MN. Neuropsychiatric findings in Cushing syndrome and exogenous glucocorticoid administration. Endocrinol Metab Clin N Am. 2013;42(3):477-88

6. Chen YF, Li YF, Chen X, Sun QF. Neuropsychiatric disorders and cognitive dysfunction in patients with Cushing's disease. CMJ. 2013;126(16):3156-60.

7. Andela CD, van der Werff SJ, Pannekoek JN, van den Berg SM, Meijer OC, van Buchem MA, et al. Smaller grey matter volumes in the anterior cingulate cortex and greater cerebellar volumes in patients with long-term remission of Cushing's disease: a case-control study. Eur J Endocrinol. 2013;169(6):811-9.

8. Andela CD, van Haalen FM, Ragnarsson O, Papakokkinou E, Johannsson G, Santos A, et al. Mechanisms in endocrinology: Cushing's syndrome causes irreversible effects on the human brain: a systematic review of structural and functional magnetic resonance imaging studies. Eur J Endocrinol. 2015;173(1):R1-14.

9. Collin C, Wade DT, Davies S, Horne V. The Barthel ADL index: a reliability study. Int Disabil Stud. 1988;10(2):61-3.

10. Wood PJ, Barth JH, Freedman DB, Perry L, Sheridan B. Evidence for the low dose dexamethasone suppression test to screen for Cushing's syndrome-recommendations for a protocol for biochemistry laboratories. Ann Clin Biochem. 1997:34(Pt 3):222-9.

11. Clarfield AM. The decreasing prevalence of reversible dementias: an updated meta-analysis. Arch Intern Med. 2003:163(18):2219-29.

12. Faustman WO, Moses JA Jr, Csernansky JG. Limitations of the mini-mental state examination in predicting neuropsychological functioning in a psychiatric sample. Acta Psychiatr Scand. 1990;81(2):126-31.

13. Roebuck-Spencer TM, Glen T, Puente AE, Denney RL, Ruff RM, Hostetter G, et al. Cognitive screening tests versus comprehensive neuropsychological test batteries: a National Academy of neuropsychology education Paperdagger. Arch Clin Neuropsychol. 2017;32(4):491-8.

14. Forget H, Lacroix A, Somma M, Cohen H. Cognitive decline in patients with Cushing's syndrome. J Int Neuropsychol Soc: JINS. 2000;6(1):20-9.

15. Dorn LD, Cerrone P. Cognitive function in patients with Cushing syndrome: a longitudinal perspective. Clin Nurs Res. 2000;9(4):420-40.

16. Forget $\mathrm{H}$, Lacroix A, Cohen $\mathrm{H}$. Persistent cognitive impairment following surgical treatment of Cushing's syndrome. Psychoneuroendocrinology. 2002; 27(3):367-83.

17. Merke DP, Giedd JN, Keil MF, Mehlinger SL, Wiggs EA, Holzer S, et al. Children experience cognitive decline despite reversal of brain atrophy one year after resolution of Cushing syndrome. J Clin Endocrinol Metab. 2005;90(5):2531-6.

18. Resmini E, Santos A, Gomez-Anson B, Vives Y, Pires P, Crespo I, et al. Verbal and visual memory performance and hippocampal volumes, measured by 3-tesla magnetic resonance imaging, in patients with Cushing's syndrome. J Clin Endocrinol Metab. 2012;97(2):663-71.

19. Pereira AM, Tiemensma J, Romijn JA. Neuropsychiatric disorders in Cushing's syndrome. Neuroendocrinology. 2010;92(Suppl 1):65-70.

20. Tiemensma J, Biermasz NR, Middelkoop HA, van der Mast RC, Romijn JA Pereira AM. Increased prevalence of psychopathology and maladaptive personality traits after long-term cure of Cushing's disease. J Clin Endocrinol Metab. 2010;95(10):E129-41.

21. Tiemensma J, Kaptein AA, Pereira AM, Smit JW, Romijn JA, Biermasz NR. Negative illness perceptions are associated with impaired quality of life in patients after long-term remission of Cushing's syndrome. Eur J Endocrinol. 2011;165(4):527-35.

22. Sonino N, Fava GA, Raffi AR, Boscaro M, Fallo F. Clinical correlates of major depression in Cushing's disease. Psychopathology. 1998;31(6):302-6.

23. Starkman MN, Gebarski SS, Berent S, Schteingart DE. Hippocampal formation volume, memory dysfunction, and cortisol levels in patients with Cushing's syndrome. Biol Psychiatry. 1992;32(9):756-65.
24. Bourdeau I, Bard C, Noel B, Leclerc I, Cordeau MP, Belair M, et al. Loss of brain volume in endogenous Cushing's syndrome and its reversibility after correction of hypercortisolism. J Clin Endocrinol Metab. 2002;87(5):1949-54.

25. van der Werff SJ, Andela CD, Nienke Pannekoek J, Meijer OC, van Buchem MA, Rombouts SA, et al. Widespread reductions of white matter integrity in patients with long-term remission of Cushing's disease. Neurolmage Clin. 2014:4:659-67.

26. de Kloet ER, Joels M, Holsboer F. Stress and the brain: from adaptation to disease. Nat Rev Neurosci. 2005;6(6):463-75.

27. Starkman MN, Giordani B, Berent S, Schork MA, Schteingart DE. Elevated cortisol levels in Cushing's disease are associated with cognitive decrements. Psychosom Med. 2001;63(6):985-93.

28. Simmons NE, Do HM, Lipper MH, Laws ER Jr. Cerebral atrophy in Cushing's disease. Surg Neurol. 2000;53(1):72-6.

29. Santos A, Resmini E, Crespo I, Pires P, Vives-Gilabert $Y$, Granell E, et al. Small cerebellar cortex volume in patients with active Cushing's syndrome. Eur J Endocrinol. 2014;171(4):461-9.

30. Maheu FS, Mazzone L, Merke DP, Keil MF, Stratakis CA, Pine DS, et al. Altered amygdala and hippocampus function in adolescents with hypercortisolemia: a functional magnetic resonance imaging study of Cushing syndrome. Dev Psychopathol. 2008;20(4):1177-89.

31. Khiat A, Bard C, Lacroix A, Rousseau J, Boulanger Y. Brain metabolic alterations in Cushing's syndrome as monitored by proton magnetic resonance spectroscopy. NMR Biomed. 1999;12(6):357-63.

32. Langenecker SA, Weisenbach SL, Giordani B, Briceno EM, Guidotti Breting LM, Schallmo MP, et al. Impact of chronic hypercortisolemia on affective processing. Neuropharmacology. 2012;62(1):217-25.

33. Liu S, Wang Y, Xu K, Ping F, Wang R, Li F, et al. Brain glucose metabolism is associated with hormone level in Cushing's disease: a voxel-based study using FDG-PET. Neurolmage Clin. 2016;12:415-9.

34. Crespo I, Santos A, Gomez-Anson B, Lopez-Mourelo O, Pires P, Vives-Gilabert $Y$, et al. Brain metabolite abnormalities in ventromedial prefrontal cortex are related to duration of hypercortisolism and anxiety in patients with Cushing's syndrome. Endocrine. 2016:53(3):848-56.

35. Starkman MN, Giordani B, Gebarski SS, Berent S, Schork MA, Schteingart DE. Decrease in cortisol reverses human hippocampal atrophy following treatment of Cushing's disease. Biol Psychiatry. 1999;46(12):1595-602.

36. Reul JM, de Kloet ER. Two receptor systems for corticosterone in rat brain: microdistribution and differential occupation. Endocrinology. 1985;117(6):2505-11.

37. Holmes MC, Yau JL, Kotelevtsev Y, Mullins JJ, Seckl JR. 11 Betahydroxysteroid dehydrogenases in the brain: two enzymes two roles. Ann N Y Acad Sci. 2003;1007:357-66.

38. van Rossum EF, Lamberts SW. Polymorphisms in the glucocorticoid receptor gene and their associations with metabolic parameters and body composition. Recent Prog Horm Res. 2004;59:333-57.

39. van Rossum EF, Koper JW, Huizenga NA, Uitterlinden AG, Janssen JA, Brinkmann $A O$, et al. A polymorphism in the glucocorticoid receptor gene, which decreases sensitivity to glucocorticoids in vivo, is associated with low insulin and cholesterol levels. Diabetes. 2002:51(10):3128-34.

40. Russcher $H$, Smit $P$, van den Akker EL, van Rossum EF, Brinkmann AO, de Jong $\mathrm{FH}$, et al. Two polymorphisms in the glucocorticoid receptor gene directly affect glucocorticoid-regulated gene expression. J Clin Endocrinol Metab. 2005:90(10):5804-10.

41. Buemann B, Vohl MC, Chagnon M, Chagnon YC, Gagnon J, Perusse L, et al. Abdominal visceral fat is associated with a Bcll restriction fragment length polymorphism at the glucocorticoid receptor gene locus. Obes Res. 1997;5(3):186-92.

42. Spijker AT, van Rossum EF. Glucocorticoid receptor polymorphisms in major depression. Focus on glucocorticoid sensitivity and neurocognitive functioning. Ann N Y Acad Sci. 2009;1179:199-215.

43. Dekker MJ, Tiemeier H, Luijendijk HJ, Kuningas M, Hofman A, de Jong FH, et al. The effect of common genetic variation in 11 beta-hydroxysteroid dehydrogenase type 1 on hypothalamic-pituitary-adrenal axis activity and incident depression. J Clin Endocrinol Metab. 2012;97(2):E233-7.

44. Ragnarsson O, Glad CA, Berglund P, Bergthorsdottir R, Eder DN, Johannsson $\mathrm{G}$. Common genetic variants in the glucocorticoid receptor and the 11 betahydroxysteroid dehydrogenase type 1 genes influence long-term cognitive impairments in patients with Cushing's syndrome in remission. J Clin Endocrinol Metab. 2014:99(9):E1803-7.

45. Starkman MN, Giordani B, Gebarski SS, Schteingart DE. Improvement in learning associated with increase in hippocampal formation volume. Biol Psychiatry. 2003;53(3):233-8. 
46. Fietta P, Fietta P, Delsante G. Central nervous system effects of natural and synthetic glucocorticoids. Psychiatry Clin Neurosci. 2009;63(5):613-22.

47. Starkman MN, Schteingart DE, Schork MA. Cushing's syndrome after treatment: changes in cortisol and ACTH levels, and amelioration of the depressive syndrome. Psychiatry Res. 1986;19(3):177-88.

48. Starkman MN, Giordani B, Gebarski SS, Schteingart DE. Improvement in mood and ideation associated with increase in right caudate volume. J Affect Disord. 2007;101(1-3):139-47.

49. Crespo I, Esther GM, Santos A, Valassi E, Yolanda VG, De Juan-Delago M, et al. Impaired decision-making and selective cortical frontal thinning in Cushing's syndrome. Clin Endocrinol. 2014;81(6):826-33.

50. Ragnarsson O, Stomby A, Dahlqvist P, Evang JA, Ryberg M, Olsson T, et al. Decreased prefrontal functional brain response during memory testing in women with Cushing's syndrome in remission. Psychoneuroendocrinology. 2017:82:117-25

51. Bala A, Lojek E, Marchel A. Cognitive functioning of patients with a PRLsecreting pituitary adenoma: a preliminary report. Neurology. 2016;86(8):731-4.

52. Henry JF, Sherwin BB. Hormones and cognitive functioning during late pregnancy and postpartum: a longitudinal study. Behav Neurosci. 2012;126(1):73-85.

53. Montalvo I, Gutierrez-Zotes A, Creus M, Monseny R, Ortega L, Franch J, et al. Increased prolactin levels are associated with impaired processing speed in subjects with early psychosis. PLoS One. 2014;9(2):e89428.

54. Torner L, Tinajero E, Lajud N, Quintanar-Stephano A, Olvera-Cortes E. Hyperprolactinemia impairs object recognition without altering spatial learning in male rats. Behav Brain Res. 2013;252:32-9.

55. Torner L. Actions of prolactin in the brain: from physiological adaptations to stress and neurogenesis to psychopathology. Front Endocrinol. 2016;7:25.

56. Montalvo I, Llorens M, Caparros L, Pamias M, Torralbas J, Gimenez-Palop O, et al. Improvement in cognitive abilities following cabergoline treatment in patients with a prolactin-secreting pituitary adenoma. Int Clin Psychopharmacol. 2018;33(2):98-102.

57. Yao S, Song J, Gao J, Lin P, Yang M, Zahid KR, et al. Cognitive function and serum hormone levels are associated with gray matter volume decline in female patients with Prolactinomas. Front Neurol. 2017;8:742.

58. Puy L, MacLusky NJ, Becker L, Karsan N, Trachtenberg J, Brown TJ. Immunocytochemical detection of androgen receptor in human temporal cortex characterization and application of polyclonal androgen receptor antibodies in frozen and paraffin-embedded tissues. J Steroid Biochem Mol Biol. 1995;55(2):197-209.

59. Tobiansky DJ, Wallin-Miller KG, Floresco SB, Wood RI, Soma KK. Androgen regulation of the Mesocorticolimbic system and executive function. Front Endocrinol. 2018;9:279.

60. Starka L, Duskova M, Hill M. Dehydroepiandrosterone: a neuroactive steroid. J Steroid Biochem Mol Biol. 2015;145:254-60.

61. Wolf OT, Kirschbaum C. Endogenous estradiol and testosterone levels are associated with cognitive performance in older women and men. Horm Behav. 2002;41(3):259-66

62. Rosario ER, Chang L, Head EH, Stanczyk FZ, Pike CJ. Brain levels of sex steroid hormones in men and women during normal aging and in Alzheimer's disease. Neurobiol Aging. 2011;32(4):604-13.

63. Morsink LF, Vogelzangs N, Nicklas BJ, Beekman AT, Satterfield S, Rubin SM, et al. Associations between sex steroid hormone levels and depressive symptoms in elderly men and women: results from the health $A B C$ study. Psychoneuroendocrinology. 2007;32(8-10):874-83.

64. Rosario ER, Chang L, Stanczyk FZ, Pike CJ. Age-related testosterone depletion and the development of Alzheimer disease. JAMA. 2004;292(12):1431-2.

65. Thilers PP, Macdonald SW, Herlitz A. The association between endogenous free testosterone and cognitive performance: a population-based study in 35 to 90 year-old men and women. Psychoneuroendocrinology. 2006;31(5):565-76.

66. Rivera-Woll LM, Papalia M, Davis SR, Burger HG. Androgen insufficiency in women: diagnostic and therapeutic implications. Hum Reprod Update. 2004;10(5):421-32.

67. Yasui T, Matsui S, Tani A, Kunimi K, Yamamoto S, Irahara M. Androgen in postmenopausal women. J Med Investig. 2012;59(1-2):12-27.

68. Davis SR, Goldstat R, Papalia MA, Shah S, Kulkarni J, Donath S, et al. Effects of aromatase inhibition on sexual function and well-being in postmenopausal women treated with testosterone: a randomized, placebocontrolled trial. Menopause. 2006;13(1):37-45.

69. Bojar I, Pinkas J, Gujski M, Owoc A, Raczkiewicz D, Gustaw-Rothenberg K. Postmenopausal cognitive changes and androgen levels in the context of apolipoprotein E polymorphism. Arch Med Sci. 2017;13(5):1148-59.

\section{Publisher's Note}

Springer Nature remains neutral with regard to jurisdictional claims in published maps and institutional affiliations.
Ready to submit your research? Choose BMC and benefit from:

- fast, convenient online submission

- thorough peer review by experienced researchers in your field

- rapid publication on acceptance

- support for research data, including large and complex data types

- gold Open Access which fosters wider collaboration and increased citations

- maximum visibility for your research: over $100 \mathrm{M}$ website views per year

At BMC, research is always in progress.

Learn more biomedcentral.com/submissions 